\title{
La interpelación de los profetas de ayer y de hoy*
}

\author{
Rafael de Sivatte, \\ Centro de Reflexión Teológica, \\ San Salvador.
}

En el marco de la preparación del segundo aniversario de los mártires del 16 de noviembre y en el ciclo de conferencias que lleva por útulo "Creer es entregar la vida", voy a hablar hoy sobre la interpelación de los profetas de ayer y de hoy y del rechazo que producen éstos entre quienes delienden las estructuras del pecado; un rechazo que en muchas ocasiones se convierte en persecución y martirio.

Vamos a ver cómo el papel y la suerte de los profelas de todos los tiempos tienen mucho en común.

\section{Se les persigue y se les mata porque estorban}

Es la primera constatación que se puede hacer cuando analizamos los testimonios bíblicos y las experiencias de cada día. Veámoslo.

En 1 Reyes 19,1ss asistimos a la purificación que realiza el legendario profeta Elías de un yahvismo al que se han ido adhiriendo cantidad de manchas propias de la religión cananea. Tras dicha purificación ejemplar por parte de Elías, los reyes de Israel - Ajab y Jezabel_, que ya habían acabado años antes con la mayoría de los profetas fieles a Yahveh, comienzan una fuerte persecución del profeta; tan fuerte que Elías no tienc más remedio que escaparse lejos

* Ponencia tenida el día 26 de octubre de 1991, en el Centro Monseñor Romero de la UCA. Dada la semejanza de situaciones de los profetas de Israel y de los mártires salvadoreños, hemos juzgado útil reproducir íntegramente los textos bíblicos para mejor comprender nuestro presente. 
de sus garras. Lo que vive en su interior nos lo muestra su tentación de dejarse morir ante el aparente fracaso de su misión. Finalmente entiende que Dios le pide que deje sucesores que sean capaces de llevar adelante su misión.

Años más tarde, otro profeta (Amós) sufre también la persecución -y posiblemente la muerte- porque resulta un estorbo para los poderosos de Israel. En Amós 7.10-17 se nos cuenta cómo el sacerdote del santuario de Betel no sólo lo denuncia ante el rey del país bajo la acusación de estar conspirando contra el rey y su gobierno y de estar inquietando así al pueblo, sino que también lo expulsa del santuario y del país, llevando adelante una auténtica campafia de desprestigio y burla, amparándose en la ley de seguridad nacional y acusándolo de desestabilizar la unión existente en Israel entre la religión y la política. La tradición judía afirma que finalmente el poder consiguió acabar con la vida del profeta.

La actuación del profeta Jeremías, a su vez, se convierte en un paradigma de lo que estoy diciendo. Basta con señalar varios pasajes para darnos cuenta de ello.

Jr 26: sermón en el templo y contra el falso templo - intento de linchamiento - juicio.

Jr 20,1-6: acción de romper el jarro - tortura - cárcel - coacción por parte de la policía para impedirle seguir actuando.

Jr 36: diclado del rollo y lectura pública por parte del amigo del profeta, Baruk - quema del rollo por parte del rey - orden de búsqueda y captura de Jeremías y de Baruk - clandestinidad.

Jr 28: enfrentamiento con el falso profeta Ananías porque éste defiende, sin base real alguna, el rápido final de la situación crítica existente entre Judá y Babilonia - intento de silenciarlo.

Jr 29: $\quad$ carta realista a los deportados judios en Babilonia diciéndoles que no abriguen demasiadas esperanzas de un rápido relomo a la tierra - acusaciones y amenazas de algunos profetas de Babilonia contra Jeremías.

Jr 34; 37-39: últimas persecuciones contra el profeta - varios encarcelamientos - condena a muerte casi ejeculada.

Jr 42 - 43: secuestro y traslado de Jeremías a Egipio por parte de sus compatriotas - según la tradición judia, asesinato del profeta por parte de estos mismos.

El profeta Urias, contemporáneo de Jeremías, es asesinado por el mismo rey por el hecho de estar actuando y hablando en la misma línea que Jeremías (cfr. Jr 26, 20-23). 


\section{LA INTERPELACION DE LOS PROFETAS DE AYER Y DE HOY}

En 2 Crónicas 24,20-22 se nos habla también de otro profeta, un tal Zacarías (no el del libro de Zacarías), asesinado.

En Nehemías 9, 26, durante la ceremonia de expiación hecha tras la restauración se dice: "nuestros padres, indóciles, se rebclaron contra ti, arrojaron tu Ley a sus espaldas y mataron a los profetas que les conjuraban a convertirse a ti".

En esta larga lista de constataciones de la persecución a muerte de los profetas debe ser situado el asesinato de Juan el Bautista, tal como nos lo narra Marcos 6, 14-29.

Y en esta misma línea debe ser situada la queja o acusación de Jesús contra los fariseos cuando, según Mateo 23, 35-37, les dice: "liene que recaer sobre ustcdes toda la sangre inocente que ha sido demamada en la tierra, desde la sangre del inocente Abel hasta la sangre de Zacarias, hijo de Barequlas, al que mataron en el altar dentro del templo"... "Ay Jerusalén, tú que matas a los profetas y apedreas a los que Dios envia".

En la obra judia "Vida de los profetas" se recoge esta misma tradición de Jesús cuando se dice que al menos seis de los profelas más conocidos (Isaías, Jeremıas, Ezequiel, Miqueas, Amós y Zacarías) murieron mártires.

Por su parte, a Jesús le tocó vivir lo mismo: intrigas, persecuciones, campanas de desprestigio, trampas y muerte.

Algo parecido se puede constatar cuando se analiza la vida de los apóstoles y de las primeras comunidades cristianas.

\section{Pero, ¿quiénes y por qué estorban?}

Estorban en el fondo aquellos que de algún modo desenmascaran las muchas idolatrías que la sociedad va creando y favoreciendo.

Aparte de la idolatría más explícila, la que hace referencia al culto de otros dioses, idolatría que cae también -aunque no con tanta frecuencia como normalmente se ha dicho- bajo la denuncia profética, las idolatrías desenmascaradas por los profetas y que mayores problemas les han provocado y les provocan, son aquellas que tienen mayores repercusiones en la vida de cada día. ¿Cuáles?

\subsection{La de la religión como privilegio o seguridad}

Es éste el primero de los grandes idolos que no favorecen la vida, el avance y la conversión, sino todo lo contrario: lo que favorecen es el conformismo y la sensación de seguridad.

Esta idolatría toma varias formas. Todas ellas producen lo mismo. 
(a) Elección: se formula diciendo que "ya que Dios nos ha elegido tenemos derecho a ser favorecidos y El tiene obligación de favorecemos". Para los profetas, en cambio, la elección (amor apasionado de Dios, pero no exclusivo) es fuente de responsabilidad y llamada a dar mayor testimonio.

Yo, sin embargo, en atención a ustedes, destruí a los amorreos, tan altos como cedros y tan forzudos como encinas, cortándoles sus ramas y arrancándoles sus raíces. Yo, también los saqué a ustedes de Egipto y los conduje por el desierto, durante cuarenta años, para que tomaran posesión del territorio amorreo. Yo, de entre sus hijos hice surgir profelas y me consagraba sus jóvenes como nazireos. ¿No es así hijos de Israel? (Am 2, 9-11).

Así como yo me dí a conocer a ustedes de un modo especialísimo de entre todas las naciones de la tierra, así también les pediré cuentas de un modo especial por su mala respuesta (Am 3,2).

Hijos de Israel, ¿no son ustedes para mí iguales que los egipcios?, dice el Señor. ¿No hice subir a Israel del país de Egipto, como a los filisteos de Caftor y a los arameos de Quir? (Am 9, 7).

(b) Guerra santa: se afirma que Dios está favoreciendo las propias guerras. Los profelas, en cambio, dicen con toda claridad que Dios no sólo no está luchando a su favor, sino que lo está haciendo en contra.

Porque así dice Yahveh a la gente de Israel: "La ciudad de la cual salían mil hombres, quedará sólo con cien, y de la que salían cien, quedará sólo con diez... ¡Ay de aquellos que suspiran por el día en que vendrá Yahveh! ¿Cómo será ese día para ustedes? Será un día de tinieblas, no de luz. Será como un hombre que huye del león y se topa con un oso, o como el que al entrar en la casa apoya su mano en la pared y lo muerde una culebra. El día de Yahveh será tinieblas y no luz, será un día sombrío, sin el menor destello" (Am 5, 3. 18-20).

¡Ay de ustedes que viven tranquilos en Sión y de ustedes que se sienten seguros en Samaria! Ustedes, los primeros de la más importante de las naciones y a quienes acude todo el mundo en Israel. Pasen a la ciudad de Calne y vean, vayan de allí a Jamat la grande y bajen después a Gat de los filisteos. ¿Valen ustedes más que esos reinos...? Ustedes tratan de alejar el día de su desgracia, pero, en realidad, están apresurando un ańo de violencia... Ustedes se ufanan por nada y andan diciendo que son imbatibles (Am 6, 1-3.14).

... y todos dicen que son amigos de Yahveh. Por eso exclaman: Si el Señor está con nosotros, ¿qué desgracia nos puede pasar? (Mi 3, 11).

(c) Templo-culto: se los toma como camino de salvación. El profetismo, en cambio, afirna que el único ayuno, la única moruficación, la única religión, el único sacrificio, el único templo que le gustan a Dios son los que llevan consigo y comprometen a una vida de justicia y de misericordia. 
Vayan al santuario de Betel para pecar. Vayan al de Guilgal y pequen más todavía. Traigan sus sacrificios cada mafiana y sus diezmos, durante los tres días. Quemen, para dar gracias, panes sin levadura, y anuncien a los cuatro vientos sus ofrendas voluntarias, pues eso les gusta a ustedes, hijos de Israel... No me busquen en Betel ni vayan a Guilgal, ni pasen a Bersebá; porque Guilgal será enviada al destierro, Betel será reducida a la nada. Busquen a Yahveh y vivirán, no sea que él se extienda como fuego sobre la casa de José y la consuma, sin que haya nadic en Betel para apagarlo... Busquen el bien y no el mal si quieren vivir, para que así Yahveh esté con ustedes, como tanto lo repiten (Am 4, 4-5; 5, 4-6.14-15).

Yo odio y aborrezco sus fiestas y no me agradan sus reuniones. No me gustan sus ofrendas ni las víclimas consumidas por el fuego; ni me llaman la atención sus sacrificios. Váyanse lejos con el barullo de sus cantos, no me molesten con la música de sus arpas... ¿Acaso me ofrecieron ustedes sacrificios y ofrendas en el desierto, durante esos cuarenta años? (Am 5, 2125).

¿De qué me sirve la multiud de sus sacrificios? Ya estoy saciado de sus animales... En realidad no me gusta la sangre, sea de ovejas, o de vacas, o de machos cabríos. Cuando vienen a presentarse delante de mi, ¿quien se lo ha pedido?, ¿por qué vienen a profanar $\mathrm{mi}$ templo? Dejense de traerme ofrendas inútiles; ;el incienso me causa horror!... iya no soporto más sacrificios ni fiestas! Odio sus lunas nuevas y sus solemnidades, se me han vuelto un peso y estoy cansado de tolerarlas. Cuando rezan con las manos extendidas, aparto mis ojos para no verlos; aunque multipliquen sus plegarias, no las escucho, porque hay sangre en sus manos (Is 1, 11-15).

¿Con qué me presentaré delante de Yahveh? ¿Cómo iré a arrodillarme delante del Dios de los cielos? ¡Me presentaré ante él trayéndole holocaustos o temeros de un año! Pero, ¿aceptará Yahveh los miles de carneros o los cientos de litros de aceite que se derramaron? ¿O será necesario que sacrifique a mi hijo mayor para pagar mi culpa, al fruto de mis entrantas por mi pecado? (Mi 6, 6-7).

¿Qué me importa a mí el incienso importado de Saba y la canela fina, que viene de un país lejano? Ya no me gustan los holocaustos, que ustedes hacen, y sus sacrificios me caen mal $(J r 6,20)$.

No confien en palabras mentirosas como éstas: ¡Miren el templo de Yahveh!, jaquí está el templo de Yahveh!, jéste es el templo de Yahveh!... Dejen de oprimir al emigrante, al huérfano y a la viuda No manchen este lugar con sangre de gente asesinada. No vayan en pos de otros dioses, para desgracia de ustedes... Pero ustedes se fían de palabras enganosas y de ningún provecho. Ustedes roban, matan, toman la esposa del projimo, juran en 
falso u ofrecen sacrificios a otros dioses que no son de ustedes... Y luego vienen a presentarse ante mí en este templo que lleva mi nombre, cuando acaban de hacer todas estas maldades. Y dicen: "iAqul estamos seguros!"... ¡Afiadan ustedes, no más, los holocaustos a los sacrificios y coman después la carne! Que cuando yo saqué a sus padres de Egipto, no les hablé ni les ordené nada referente a sacrificios y holocauslos. Lo que les mandé, más bien, fue esto: "Escuchen mi voz, y yo seré su Dios y ustedes serán mi pueblo. Caminen por el camino que les indiqué para que siempre les vaya bien". Pero ellos no me escucharon... sino que siguieron la inclinación de su corazón malvado, me dieron la espalda y me volvieron la cara (Jr 7, 4-10.2124).

Según dicen, me andan buscando día a día... Y se quejan: "¿Por qué ayunamos y tú no lo ves, nos humillamos y tú no lo tomas en cuenta?" Porque en los días de ayunos ustedes se dedican a sus negocios y obligan a trabajar a sus obreros. Ustedes ayunan entre peleas y contiendas, y golpean con maldad. No es esta clase de ayunos como los de hoy día los que lograrán que se escuchen sus voces allá arriba. No es así como debe ser el ayuno que me gusta o el día en que el hombre se humilla. ¿Acaso se trata nada más que de doblar la cabeza como un junco o de acostarse sobre sacos y ceniza? iA eso llamas ayuno y día agradable a Yahveh (Is 58, 2-5).

(d) Sión: lugar santo de la ciudad santa, donde Dios está presente, entendida esta presencia como algo mágico: por estar ahl, Dios está obligado a defenderlos; nada por tanto les puede pasar ni a la ciudad misma ni a quienes viven en ella. El profetismo afirma, en cambio, que sí puede pasar lo peor; y el motivo es que la ciudad de la que tanto se ufanan está construida sobre sangre.

Pero precisamente por sus maldades, Sión va a quedar corno un potrero arado, Jerusalén será reducida a escombros y el cerro del templo será cubierto por el bosque (Mi 3, 12; cfr. Jr 26, 18).

iAy de la rebelde, de la manchada, de la ciudad opresora! No ha hecho caso a mi llamado..., nunca ha tenido confianza en Yahveh ni se ha acercado a su Dios. Sus reyes se comportan como leones que rugen; sus gobemantes son como lobos noctumos que no guardan ni un hueso para el día siguiente... Sin embargo, en su interior está Yahveh, que es justo y que nunca comete injusticia... He borrado del mapa a las naciones... Yo pensaba: "Si al menos lú me temieras... Pero ellos, al contrario, se han apresurado a comportarse mucho peor aún. Por esto esperrenme, les dice Yahveh, para el día en que yo venga a acusarlos; cuando ordene... que se reúnan las naciones... para descargar sobre ustedes mi enojo..., entonces todo el territorio será consumido por el fuego de mis celos (So 3, 1-8).

... trataré esta casa mía como traté el santuario de Silo, y pondré a Jerusalén como ejemplo: todas las ciudades reconocerán que yo la maldije (Jr 26,6$)$. 
Pues así habla Yahveh...: "Corten árboles y construyan un terraplén frente a Jerusalén, que es una ciudad mentirosa y que oprime a todo el mundo. Porque como se saca agua de un pozo, asi brota de ella la maldad. Alll sólo se oye hablar de violencia e injusticia; y mis ojos están siempre viendo el sufrimiento y el mal trato" (Jr 6, 6-7).

\subsection{La monarquía y el poder}

Sería fuente de seguridad si los reyes no tomaran el poder como un idolo. como una falsa divinidad, que exige que se le ofrezcan muchos sacrificios, sino como servicio. De hecho, aunque a las corrientes proféticas existentes en el momento de originarse la monarquía en Israel no les parecía muy bien la inslauración de esta instilución (cfr. Jc 9, 7-20; 1 S 8, 1-22), lucharon para que al menos pudiese tener un papel positivo: el de ayudar a la relación con el Dios de la liberación y de la vida y el de velar para que en la sociedad hubiese justicia y solidaridad.

Lo que está claro es que casi nunca la monarqufa realizó dicho servicio al pueblo. Y a causa de esto se explican las posuras de los profetas.

Unos profetas rechazan la monarquía de un modo categórico. La consideran el pecado original de todos los males de Israel.

En Guilgal (lugar donde se nombró rey a Saúl) salió a relucir toda su maldad. Allí fue donde les tomé odio. Los echare de mi casa por toda su conducta depravada; no les tendré más carifio, pues todos sus reyes me han desobedecido (Os 9, 15).

Israel, yo que era tu socorro, voy ahora a destruirte. ¿Dónde está, pues, tu rey para que te salve? ¿Y tus generales, para que te protejan? ¿No eran ellos los que tu me pediste? Te di un rey para que no me molestaras más, y ahora te lo quilo porque ya me aburriste (Os 13, 9-11).

Otros profelas aceptan la monarquía, pero de un modo critico. Asi aparece en las relaciones existentes entre el profeta Isaias y el rey Acaz (cfr. la denuncia y la acusación de desconfianza en Yahveh que le hace en el libro del Emmanuel, Is 7-12) y entre el profeta Jeremías y los reyes Joaquín I y Sedecías de Jerusalén (cfr. Jr 21, $11-23,8$ ).

...Hagan justicia correclamente cada dia, libren al oprimido de las manos del opresor... Practiquen la justicia y hagan el bien: Libren de la mano del opresor al que fue despojado; no maltraten al emigrante ni al huérfano ni a la viuda; no les hagan violencia ni derramen sangre inocente en este lugar (Jr $21,12 ; 22,3)$.

¡Ay de aquel que construye su casa con cosas robadas, edificando sus pisos sobre la injusticia! ¡Ay de aquel que se aprovecha de su projimo y lo hace 
trabajar sin pagarle su salario! Tú piensas: "Me voy a construir un gran palacio..." ¿Acaso serás más rey con tener más cedro?... no piensas sino en tu interés, y en derramar sangre, y mantener la opresión y la violencia. Esto sí que te gusta (Jr 22, 13-17).

Un tercer grupo de profetas tiene palabras muy utópicas sobre la venida de un rey ideal, tan diferente y bueno que pone en cuestión cualquier concreción del poder que se haya dado hasta el momento.

Así dice Yahveh: "Llega el día en que yo haré surgir un hijo de David que se portará como rey justo y prudente. El gobernará este país según la justicia y el derecho. En aquel uempo, Judá gozará de paz, e Israel pernanecerá seguro. Y éste es el nombre que le darán 'Yahveh-nuestra-justicia'" (Jr 23, 56; cfr. Is 8, 23b-9,6; 10, $33-11,9$; Ez 37, 15-28).

\subsection{Las superpotencias}

Es indudable la existencia de potencias y de situación imperialista en el antiguo "próximo oriente": Egipto, imperios mesopotámicos, imperio medopersa, Grecia, Roma. Cada uno de estos imperios trató en su momento de alinear consigo mismo a los pequeños países. La razones que les movieron son las de siempre: las económicas (materias primas, impuestos, esclavos, comercio), las militares (experimentación y comercio de armas) y las geopolíticas (lugares de paso, zonas de influencia, efecto-dique contra la otra superpotencia). Todo esto motivó un continuo intervencionismo en la zona, con el agravante que las superpotencias siempre procuraron pelear fuera de su territorio. La postura profética frente a esta realidad tiene muchos matices. Veámoslos.

(a) Aparente compatibilidad de los imperios y voluntad de Dios; lo que se quiere subrayar es que la historia no se escapa, al menos a la larga, a los proyectos o planes salvíficos de Dios.

En ese día el Señor, con una navaja alquilada al otro lado del río, raspará la cabeza, el cuerpo y la barba (Is 7, 20).

...el Señor hará subir contra ellos las aguas embravecidas y profundas del rio Eufrates (que es el rey de Asiria con todo su poder). Este se saldrá de su lecho y correrá por todas sus riberas; llegará hasta Judá inundándolo todo,... (Is 8, 7-8).

¡Ay de Asur, que es el bastón de mi ira, el garrote que usa mi furor! Yo lo he enviado contra una nación impía, contra un pueblo que me molesta, para que lo saquee y le quite todo lo que tiene... (ls 10, 5-6).

Cfr. Is 5,$26 ; 28,2-3$.

...voy a mandar a buscar a Lodas las naciones del norte, dice Yahveh, y a mi mayordomo, Nabucodonosor, rey de Babilonia, y los echaré contra este país 
y sus habitantes (Jr 25, 9).

Yo hice... la tierra...y la doy a quien se me antoje. Ahora bien, actualmente, yo he puesto todos estos paises en manos de mi mayordomo Nabucodonosor, rey de Babilonia... (Jr 27, 5-17)

Cfr. Jr 29, 4-9.

En Ezequiel 17, 1-21 el profeta critica a Sedecías por haber roto el pacto con Babilonia; tal crílica parece estar hecha desde la convicción de que Babilonia es "instrumento del Señor".

En Isaías 41, 1-5; 45, 1-8; 48, $12-15$ el profeta del exilio llama a Ciro "pastor", "ungido", "amigo" de Dios. Parece, pues que acepta sin más la realidad del imperio medo-persa.

Así pues, los profetas parecen aceptar en parte a los imperios, pero siempre con ciertas condiciones, es decir, siempre y cuando actúen como instrumentossiervos-amigos de Dios, para purificar al pueblo pecador, para ayudar a volver a Dios, para liberar al pueblo de otra dominación. Además afirman, en todo caso, que la dominación de cualquier superpotencia siempre será transitoria.

Oh pueblo mío, que vives en Sión, no le tengas miedo a Asur, que te da de palos, o que te pega con su bastón, como hacía Egipto. Porque dentro de muy poco tiempo, desaparecerá mi enojo contra ti, y mi cólera los destruirá. Yahveh... levantará su bastón sobre el mar, como lo hizo en Egiplo. Entonces, su carga se caerá de tu espalda y su yugo dejará de pesar en tu cuello (Is 10, 24-27; cfr. Is 14, 24-25).

Mas, cuando se cumpla este tiempo, castigaré al rey de Babilonia y a su nación por sus crímenes; castigaré al país de los caldeos, dejándolos abandonados para siempre (Jr 25, 12; cfr. Jr 27, 7; 29, 10; 51, 59-64).

Acaban, pues, rechazando a los imperios. Pero, Łpor qué razones? ¿Es sólo por las blasfemias proferidas por la superpotencia contra Yahveh ( $c f r$. Is 36, 4$6.8-20 ; 37,10-12$ ). En parte, sí. Pero la razón profunda parece ser otra.

El (el imperio asirio), en cambio, no piensa lo mismo, ni lo cree así su corazón, pues su intención es destruir y hacer pedazos numerosas naciones. Dice: “... Así como mi mano ha alcanzado los reinos de los ídolos, en que las estatuas eran más numerosas que las de Jerusalén y Samaria; como he tratado a Samaria y a sus ídolos, ¿no seré capaz de hacer lo mismo con Jerusalén y sus imágenes?"... El Sen̂or castigará la soberbia del corazón del rey de Asiria y la mirada despreciativa de sus ojos. Porque dijo: "Con la fuerza de mi brazo he hecho esto, y con mi capacidad, pues soy inteligente; he hecho retroceder las fronteras de los pueblos y me he apoderado de sus tesoros. Yo como soberano hice bajar de su trono a sus reyes. Mi mano ha tomado, como se toma un nido, las riquezas de los pueblos. Como se 
recogen huevos botados, así me he apoderado de toda la tierra y no hubo quien aleteara ni abriera el pico ni piara". ¿Acaso el hacha se cree más que el leñador, o la sierra, más que el aserrador? ¡Como si el basión mandara a quien lo usa o el palo moviera al que no es de madera! (Is 10, 5-15).

Estos profetas, pues, van aprendiendo de la experiencia que Dios no quiere, ni puede querer, la opresión; la opresión sigue necesariamente a la instauración de cualquier superpotencia.

(b) Rechazo de las potencias desde el nacionalismo: no llegarfa a ser, por tanto, un rechazo del imperialismo en cuanto tal, sino sólo en cuanto que domina y oprime al pueblo judío.

Tal parece ser la postura de Sofonfas y de Nahum cuando anuncian o cantan alegremente la caída del imperio asirio y de su capital Nínive en manos del nuevo imperio babilonio. También las duras palabras de Jeremias 50-51; Isaías 13; 21, 1-10; 47 contra Babilonia parecen nacer más que de un antiimperialismo de un nacionalismo. Lo mismo ocurre con el mensaje dado por Zacarías y Ageo, veinte antos después del edicto de Ciro, por el que se concedía la libertad a los judíos y se les animaba a retomar a la patria; estos dos profetas parecen caer en la cuenta de que la libertad conseguida es muy limitada y arremeten con dureza contra el imperio medopersa, afirmando la esperanza de que los imperios se destruyan entre ellos, ya que se han excedido en sus atribuciones y se han aprovechado de los momentos de cólera de Dios contra su pueblo.

(c) No al imperialismo en cuanto tal.

Esla es la postura que más nos interesa aquí. Es la que aparece en algunos textos de profetas anónimos, contemporáneos de Jeremfas, en relación a Babilonia. En ellos, la ira de Dios es provocada por la actitud imperialista de Babilonia.

Ya vengo a ti, cerro destructor, que arruinabas la faz de la tierra. Apenas extienda mi mano contra ti, te haré rodar de lo alto de las rocas y te convertiré en un cerro quemado. Jamás sacarán de ti una piedra de cimientos, ni tampoco buscarán piedras para volver a edificarte. Serás un montón de ruinas para siempre (Jr 51, 25-26).

En otros textos parece que más que el orgullo del rey lo que se subraya es la perspectiva ética y universal de la actitud cruel del imperio; se acaba subrayando que la opresión sobre ouros, destruye al propio imperio.

Cómo ha terminado el tirano y acabado su arrogancia! Yahveh ha rolo el palo de los malvados, el bastón de los opresores, que les pegaba a los pueblos con rabia, golpeándolos sin cesar, y oprimia con furia a las naciones, persiguiéndolas sin descanso... Bajo la tierra, los muertos se agitan por ti..., se levantan de sus tronos los reyes de los pueblos... y te dicen: "iTú también 
has sido tirado al suelo y ahora eres igual a nosotros!... ¿Cómo carste desde el cielo, estrella brillante, hijo de la Aurora? ¿Cómo tú, el vencedor de las naciones, has sido derribado por tierra? En tu corazón decías: "Subiré hasta el cielo..., seré igual al Altísimo". Mas jay! has caído en las honduras del abismo... Los que te ven... dicen al verte: "Este es el que espantaba a la tierra, que hacía temblar a los reinos, que convertía al mundo en un desierto, que destruía las ciudades y nunca abría la cárcel a los presos"... No tendrás la sepultura de los reyes, porque has desolado tu tierra y asesinado a tu pueblo... (Is 14, 4b-21).

También el profeta Habakuk parece rechazar de parte de Dios el imperialismo en cuanto tal. Parte de la experiencia de injusticia sufrida por el pueblo a causa del rey Joaquín I. Ante la respuesta divina de que ya viene Nabucodonosor para hacer justicia, el profela se queja de que el nuevo imperio babilonio, como todo imperio, también seră opresor. Se pone, en consecuencia, el profeta a la espera de una respuesta más convincente de Dios. Esta le llega ( $f r$ r. Ha 2) en la siguiente forma: la venganza de Dios ya está cerca; todos los países - saqueados, chafados, humillados-, la naturaleza entera y Dios castigarán a la nación opresora; ésta, oprimiendo, se ha puesto ella misma en peligro.

Finalmente, el apocalíptico Daniel es la muestra más clara de esta convicción de que Dios rechaza a todo imperio. El contexto es el siguiente. El helenista Antíoco IV aprovecha las tensiones y luchas internas entre los judios para dominarles mejor. Ante el intento por su parte de destruirles su cultura y su fe, convirtiéndose de este modo en el ujpo del opresor, muchos judíos se rebelan y se enfrentan a él. Comienza una auténtica resistencia contra el opresor.

En la segunda parte (Dn 8-12) aparece la preocupación por la opresión del pueblo y el deseo de animarlo. La primera parte, sin embargo, (Dn 2-7) es la que resulta más original y teológica. Su esquema es el siguiente:

a. sueño de cuatro reinos a los que seguirá el último de Dios (Dn 2)

b. hechos de mártires o testimonios de fe: en el homo (Dn 3)

c. juicio sobre los reyes ( $\mathrm{Dn} 4-5$ )

b. hechos de mártires o testimonios de fe: leones (Dn 6)

a. sueño de cuatro reinos a los que seguirá el hijo del hombre ( $\mathrm{Dn} 7$ )

El juicio sobre los reyes significa que Dios es rey y señor sobre todos los reyes; castiga a quien no le reconoce.

La parte más original es la de los sueños: el de la estatua y el de las cuatro bestias nos hablan de imperios dominadores, de caída de dichos imperios y de venida de uno nuevo y delinitivo que los vencerá, una vez instaurado por Dios mismo sin intervención humana, cl del pueblo de los santos del Alúsimo. 
Dios, por tanto, está contra todos los imperios; su imperio nada tiene que ver con ellos. Daniel, pues, denuncia con fuerza el imperialismo, haciendo servir unas imágenes que nos hablan de arrogancia vacía y sin fundamento de tales imperios (estatua) y de su carácter bestial y brutal (animales).

\section{Conclusión}

En último terrmino, el juicio que el profetismo hace sobre las superpotencias es que: siempre son idolátricas, siempre se sienten autosuficientes, siempre caen en el orgullo, siempre son bestiales, siempre son inhumanas.

El único imperio aceptado por el profetismo es el del hijo del hombre: éste destruirá lodo imperio e instaurará un reino de fraternidad en la línea de Isafas 2 , 1-5, en donde se habla de un futuro sin naciones opresoras e imperialistas, un futuro sin fronteras, un futuro en que habrá justicia y solidaridad entre todas las naciones.

\subsection{Confianza en los pactos y en las armas}

Con frecuencia Israel y Judá fueron obligados a hacer pactos por las potencias. En tales casos, a los profetas no les quedó oura cosa que animar a su pueblo a aguantar aquella situación impuesta. Pero en otros casos, los reyes de Judá y de Israel hicieron pactos voluntarios con dichas potencias. La razón de tales pactos podía ser el formar coalición contra otros imperios o reinos, el ser defendidos contra los ataques de enemigos o el recibir su apoyo en golpes de Estado para tomar el poder. En estos casos, los profetas si tomaron una postura muy fuerte contra dichos pactos. Veamos algunos textos.

Efrafm sabe que está enfermo, y Judá, que ciene úlceras. Por eso Efraím ha ido a Asiria y ha mandado mensajeros al gran rey; pero éste no podrá sanarlos ni curarles sus llagas. Porque yo me portaré como un león con Efraim, y como un cachorro con la gente de Judá. Yo, sí, yo mismo lanzaré un zarpazo y huiré, me llevaré mi presa y nadie me la podrá quilar. Pero ahora me vuelvo a mi casa, hasta que se reconozcan culpables y vengan a verme, pues en su angustia tratarán de encontrarme (Os 5, 13-15).

Efraím se mezcla con ouros pueblos. Efraím es una tortilla que se ha quemado por un solo lado. Los extranjeros consumen sus energias sin que se dé cuenta. Su cabeza está sembrada de canas y él no lo nota. Su misma arrogancia condena a Israel, pero no se han vuelto a Yahveh, su Dios, ni tratan, a pesar de todo, de buscarlo. Elraím es como una paloma tonta y sin juicio, pues o bien Ilaman a Egipto, o bien parten a Asiria. Pcro, adonde quiera que vayan, yo les pondré una trampa y caerán en ella como las aves del ciclo, y los castigaré por todas sus maldades (Os 7, 8-12).

Como siembran vientos, cosecharán tempestades. Su trigo no echará espigas, 
la espiga no dará harina, y si llega a dar algo, se la comerán los extranjeros. Israel ha sido devorado y ahora aparece en medio de las naciones como una cosa que no sirve. Efraím era un burro orgulloso. Pero miren cómo subió a Asiria llevando regalos a sus amantes. Sin embargo, por más que se hayan hecho de arnigos en las naciones, pronto los voy a dispersar y dentro de poco no podrán ungir más reyes ni príncipes (Os 8, 7-10).

Efrafm me ha rodeado de mentira, la gente de Israel de falsedad; pero Judá sigue todavia a su Dios, es fiel con el Santo. Efraím se llena de viento, corre tras el viento de oriente, sin cesar multiplica la mentira y la violencia, hace alianza con Asiria y lleva perfumes a Egipto (Os 12, 1-2).

"Asiria no nos salvará ni confiaremos más en los caballos, ni a la estatua que hicieron nuestras manos volveremos a decirle: Dios nuestro" (Os 14, 4).

¡Oigan, herederos de David! ¿No les basta molestar a todos, que también quieren cansar a mi Dios? El Señor, pues, les dará esta señal: La joven está embarazada, y da a luz un hijo varón a quien le pone cl nombre de Emmanuel (tú no quieres pedir seffal porque esto te exigiría confiar en el Señor; prefieres en cambio, pedir ayuda a Asiria, creyendo que te va a salvar) (Is 7, 13-14).

¡Ay de estos hijos rebeldes, dice Yahveh, que ponen en práctica unos proyectos que no son los míos y que se comprometen con pactos que no les he sugerido, de modo que acumulan así pecados y más pecados. Han partido para Egipto, sin escuchar mis consejos, para pedirle asilo al faraón y refugiarse bajo la sombra de Egipto. Ustedes esperan la protección del faraón, pero serán defraudados y se avergonzarán de haber buscado la sombra de Egipto. Pues sus ministros han ido a Zoan, y sus embajadores han llegado hasta Hanes. Todos han traído regalos a un pueblo que no les servirá de nada y que no les conseguirá ni ayuda ni socorro, sino deshonra y malos ratos (Is $30,1-5)$.

¿Para qué llamas a Egipto?, ¿acaso te sanarán las aguas del Nilo? ¿Y para qué llamas a Asur?, ¿apagarán tu sed las aguas del rio? (Jr 2, 18).

No te des tanta prisa para cambiar us amistades. Como te engañó Asur lambién te engañará Egipto. También de ahí saldrás con las manos en la cabeza, porque Yahweh ha rechazado a aquellos en que confías, y no te irá bien con ellos (Jr 2, 36-37).

Samaría que era mía se prostituyó, me abandonó y se enamoró locamente de los guerreros asirios, vestidos elegantemente, gobernadores y jefes, jóvenes hermosos y caballeros auléticos. Se manchó con ellos, con los más escogidos de los asirios; después de haberse enamorado de ellos, se manchó con sus idolatrías. Sin embargo no olvido su prostitución con los egipcios; por eso la 
entregué en manos de sus amantes, en poder de los asirios, de los que se había enamorado locamente. Estos la llenaron de vergllenza, le arrebataron sus hijos e hijas y, a ella, la mataron a espada. Samaria llegó a ser un ejemplo para las naciones por el escarmiento que se hizo en ella (Ez 23, 5$10 ; c f r .16,26-29 ; 23,11-27$ ).

En su conjunto, pues, Oseas, Isaías, Jeremias y Ezequiel parecen afirmar lo siguiente sobre tales pactos: con ellos las potencias buscan siempre su propio provecho; son una manera de autodivinizarse, de querer el trato de dioses, de exigir una confianza que siempre resulta falsa; tales pactos nunca producen salvación ya que son idolátricos, vacíos, sin base alguna furme. Los profelas sólo ven un camino de salvación, la unión fraternal de todos en tomo al Seffor Yahveh.

Respecio a las armas, no es fácil ver la postura profética, ya que éstos se mueven en un ambiente guerrero en que Dios es presentado como guerrero luchando en favor de su pueblo. Lo importante es descubrir la línea progresiva y la profundización en lo que significa realmente la fe en el Dios liberador. En la práctica va quedando desenmascarado el ídolo de la guerra y de las armas. Los pasos que se van dando son los siguientes:

(a) Se contrapone en primer lugar la confianza en las armas y la confianza en Yahveh.

La misma fuerza de los jueces liberladores está en dejarse llevar por la fuerza del Espíritu de Yahveh, la que les lleva a mantener unido al pueblo; su fuerza, en cambio, no está en la cantidad de soldados y armas.

En el combate desigual entre David y Goliat aparece con claridad la misma afirmación cuando David le dice a Goliat:

Tú vienes contra mi con la espada, la lanza y las flechas, pero yo voy contra ti en nombre de Yahveh Sebaot... Todos... reconocerán que Yahveh no vence con la espada ni con la lanza... (1S 17, 38-54).

Los profetas hablan continuamente del tema de las armas. Las equiparan a los ídolos a los que se sacrilica las vidas humanas, las desenmascaran como algo que es falso y que no puede dar seguridad alguna, las ven como que se ponen en contra de aquellos que han confiado en ellas.

...los salvaré por Yahveh su Dios. No los salvaré con arco, ni espada, ni guerra, ni con caballos, ni jinetes (Os 1, 7b).

Israel se ha olvidado de su creador y construye palacios. Judá, por su parte. multiplica las ciudades fortificadas. Pero yo prendere fuego a sus ciudades e incendiaré a sus castillos (Os 8, 14).

Ya que uí te ufanabas de tus carros y de tu ejército numeroso, reinara la confusión en tus ciudades y serán demolidas tus fortalezas, como paso 
cuando Salmán destruyó a Betarbel, y que aplastaron a las madres con sus hijos entre los brazos (Os 10, 13b-14).

Asiria no nos salvará ni confiaremos más en los caballos, ni a la estatua que hicieron nuestras manos volveremos a decirle: "Dios nuestro" (Os 14,4).

En la conversión y en la calma está la salvación, y su seguridad, en una perfecta confianza. Pero ustedes no lo han aceptado y han dicho: " $j$ Mejor huiremos a caballo!" Pues bien, ¡huyan no más! Y han añadido: "En rápidos carros" ¡Muy bien, también los perseguidores correrán rápidamente! (Is 30, 15-16).

¡Ay de los que bajan a Egipto, por si acaso consiguen ayuda! Pues confían en la caballería, en los carros de guerra, que son numerosos, y en los jinetes, porque son valientes. ¿Por qué no hicieron caso del Santo de Israel y no consultaron a Yahveh? Porque él también es hábil en proporcionar desgracias, y no cambia su palabra. Pedirá cuenta a la banda de los malvados y el socorro con el que contaban, no llegará. El egipcio es un hombre y no un dios, y sus caballos son carne, y no espíritu. En cuanto Yahveh extienda su mano, vacilará el protector y caerá quien buscaba protección: juntos perecerán (Is 31, 1-3).

Aquél (Babilonia) los pesca a todos con su anzuelo, los saca con su red y los va amontonando con su malla. Feliz y contento por su pesca, le ofrece sacrificios a su red, quema incienso a sus mallas, pues a ellos les debe que haya pescado tanto y tenga que comer en abundancia. ¿Seguirá, pues, vaciando constantemente su red, masacrando sin picdad a las naciones (Ha 1, 16-17).

Había dos mujeres, hijas de la misma madre. Se prostituyeron en Egiplo en su juventud. Oholá (Samaria)... se enamoró perdidamente de sus amantes, los asirios... lodos ellos jóvenes apuestos y hábiles caballeros... Por eso yo la entregué en manos de los asirios. Estos descubrieron su desnudez, se llevaron a sus hijos e hijas, y a ella misma la mataron a espada... Su hermana Oholibá (Jerusalén) vio esto, pero...se enamoró de los asirios...hábiles caballeros y todos ellos jóvenes apuestos... vio hombres pintados en la pared, figuras de caldeos...con aspecto de escuderos todos ellos... y se enamoró... Pero después... vendrán contra ti desde el norte carros y carretas...te opondrán el pavés, el escudo y el casco... (Ez 23).

\section{(b) Se propone la utopía de un mundo sin armas}

Los profecas dan un paso más. Prescindiendo de la mayor o menor conveniencia política de confiar o no en las armas, comienzan a hablar de un futuro (definitivo y hacia el que se debe caminar), en términos que interpelan, un futuro sin arma alguna, un futuro que se debe construir con Dios. 
Ese día haré un pacto con las fieras salvajes, con las aves de rapifa y las serpientes de la tierra, para que no le hagan dafio. Romperé el arco y la espada, alejaré la guerra de su tierra y haré que la gente duerma segura ahí (Os 2, 20).

Aquel día, dịce el Señor, te sacaré uus caballos y destruiré tus carros, borraré de tu suelo tus ciudades y demoleré todas tus fortalezas, arrancare de tus manos todas tus supercherías, ya no podrás ver la suerte en tu mano y no tendrás más a tus adivinos. Te arrebatare tus estatuas y ous idolos que tienes junto a ti; y así no podrás más prosternarte delante de algo hecho con tus manos (Mi 5, 9-12).

El yugo que soportaban, y la vara sobre sus espaldas, el látigo de su capataz, tú los quiebras como en el día de Madián. Las botas que hacían retumbar la tierra y los uniformes manchados de sangre van a ser quemados: el fuego los devorará. Porque un niño nos ha nacido, un hijo se nos ha dado... Este es... el príncipe de la paz. Su imperio no tiene límites, y, en adelante, no habrá sino paz para el hijo de David y para su reino. El lo establece y lo sostiene por el derecho y la justicia, desde ahora y para siempre (Is 9, 3-6).

Una rama saldrá... Sobre él reposará el Espíritu de Yahveh... hará justicia a los débiles y dictará sentencias justas a favor de la gente pobre. Su palabra derribará al opresor, el soplo de sus labios matará al malvado... El lobo habitará con el cordero, el puma se acostará con el cabrito, el ternero comerá al lado del león y un niffo chiquito los cuidará... El niffo de pecho pisará el hoyo de la víbora... No cometerán el mal, ni dafiarán a su projimo en lodo mi cerro santo, pues, como llenan las aguas el mar, se llenard la tierra del conocimiento de Yahveh (Is 11, 1-9).

En el futuro, el cerro de la casa de Yahveh será puesto sobre los altos montes y dominará los lugares más elevados. Irán a verlo todas las naciones y subirán hacia él muchos pueblos, diciendo: "Vengan, subarnos al cerro de Yahveh..., para que nos ensente sus caminos... Porque la ensefianza irradia de Sión, de Jerusalén sale la palabra de Yahweh". El Sefior gobemará las naciones y enderezará a la humanidad. Harán arados de sus espadas y sacarán hoces de sus lanzas. Una nación no levantará la espada contra otra, y no se adiestrarán para la guerra (Is 2, 1-5).

Así pues, los profetas afurman en último término que la última palabra de Dios es la de una sociedad y una humanidad sin armas.

\subsection{La ambición de riqueza y de poder}

Es éste uno de los temas más fundamentales entre los profetas. Es uno de los ídolos más frecuentes y que producen más muerte. En la historia de Israel, la entronización de este ídolo se fue haciendo cada vez con más fuerza. 
De hecho, en los tiempos anteriores a la existencia de Israel, tiempos en que los antepasados de Israel vivían como pastores seminómadas, se daba una mayor unidad familiar o tribal. Había una mayor igualdad y solidaridad entre todos. No había una injusticia social institucionalizada. Es más, el mismo grupo se preocupaba por defender a sus seres más indefensos.

Con la sedentarización comenzó a darse mayor importancia a la posesión de la tierra. Al principio todavía no suponía diferenciación. Se preparaba el terreno entre todos los miembros del clan y se repartía a continuación a suertes por familias, de un modo más o menos proporcional.

El problema se empezó a agudizar con la monarquía. La organización social introdujo nuevos hábitos. Comenzó la inmigración hacia las ciudades, la organización del comercio, la necesidad del crecimiento del patrimonio real (para las herencias de los príncipes y para pagar los servicios de los militares), la acumulación de tierras (de hecho el rey pagaba los servicios de los cortesanos y de los militares con tierras), la compra-venta de tierras, la ambición de poseer. Se rompe así la igualdad. Comienzan a existir esclavos, trabajadores explotados, seres indefensos. Aumenta el poder de la burocracia, del ejército, de los jueces. La diferenciación económica y social se conviente en un hecho: enriquecimiento-empobrecimiento. Las guerras contribuyen al aumento de las diferencias.

Es verdad que las diferentes legislaciones de Israel intentaron corregir estas siluaciones. Ejemplos claros de esto son: las leyes de reparto de la tierra, de respeto a los más pobres, de justicia en los tribunales, de préstamos sin interés, del año sabático para liberar a los esclavos y para perdonar las deudas, del salario justo, del año jubilar, de la prohibición de esclavitud por deudas. Pero estos intentos no sirvieron para mucho. Los primeros que no cumplieron con su obligación de ayudar a que se pusieran en práctica fueron los reyes, quienes además continuamente violaron las mismas leyes.

Van apareciendo, en consecuencia, los profetas quienes van a denunciar con fuerza lodas estas violaciones de la fraternidad, poniéndoles nombres muy concretos. Denuncian el conjunto, denuncian el lujo, denuncian el latifundismo, denuncian el comercio fraudulento, denuncian la injusticia en los tribunales, denuncian la explotación del obrero. Pero lo hacen convencidos de que, como dice Amós: "Quien explota al pobre profana mi santo nombre" (Am 2, 7). Y lo hacen porque lo que quieren con toda su alma es que haya una conversión en la sociedad, un cambio profundo hacia la justicia social y un compromiso de todos por vivir fratemal y solidariamente.

Veamos, pues, estas denuncias por temas.

Contra impuesios injustos

Am 5, 11: Pues bien, ya que ustedes han pisoteado al pobre, exigiéndole una parte de su cosecha, esas casas de piedras canteadas que 
edifican no las van a ocupar, y de esas cepas escogidas que ahora plantan no probarán el vino.

Contra la ambición y la avaricia que destruyen la vida de los pobres

Am 2, 6b-7: Porque venden al inocente por dinero, y al necesitado por un par de sandalias. Pisotean a los pobres en el suelo y les impiden a los humildes conseguir lo que desean.

Is 1,23: Tus jefes son unos rebeldes, amigos de ladrones. Todos esperan recompensa y van detrás de los regalos. No hacen justicia al huérfano ni atienden la causa de la viuda.

Is 3,14s: Yahveh ha demandado ante la justicia a los ancianos y a los jefes de su pueblo. "Ustedes son los que han devorado los frutos de la viña, en sus casas están los despojos del pobre. ¿Con qué derecho oprimen a mi pueblo y pisotean a los pobres?".

Is 5, 8-10: ¡Ay de aquellos que, teniendo una casa, compraron el barrio poco a poco! ¡Ay de aquellos que juntan campo a campo! ¿Así que ustedes se van a apropiar de todo y no dejarán nada a los demás? En mis oídos ha resonado la palabra de Yahveh de los ejércitos: "Han de quedar en ruinas muchas casas grandes y hermosas, y no habrá quien las habite. Diez cuadras de viña apenas darán un barril de vino, y un quintal de semilla, sólo dará un puñado".

Mi 2,1-2.8-9: ¡Ay de ustedes que meditan la injusticia, que toda la noche traman el mal, y al amanecer lo ejecutan, porque está a su alcance. Si les gustan campos, se los roban, o unas casas, se las toman. Se apoderan de la casa y de su dueño, de un hombre y de su propiedad. Pero son ustedes los enemigos de mi pueblo, pues le quitan su manta al hombre bueno y tratan como si estuviera en guerra al que vive tranquilo. Arrancan de sus hogares tan queridos a las mujeres de mi pueblo, y les quitan a sus hijos la liberiad que yo les había dado.

So $1,8 \mathrm{~b}-9$ : ...castigaré a los ministros, a los hijos del rey y a todos los que visten a la moda extranjera. Les dare también su merecido a todos los que pasan por el umbral sin pisarlo y a los que amontonan en la casa de su Seftor el producto de sus crímenes y robos.

Jr 2, 34: Mira tus manos manchadas de sangre, no de bandidos sorprendidos en el crimen sino que de inocentes. 
Ez 22 ,29: La gente del país comete violencia y se entrega al pillaje, pisotea al pobre, maltrata al indigente y veja al emigrante sin razón alguna.

Contra el lujo, grandes fiestas, grandes construcciones montadas sobre la opresión y la despreocupación de lo que está ocurriendo

Am 3, 9-10.15: Marchen junto a Samaria, situada en las montanas, para que vean los desórdenes que hay en esa ciudad o los crímenes que en ella se cometen. No puede ser honrada la conducta de aquellos que amontonan la rapina y el fruto de sus salteos en sus palacios. Destruiré las mansiones para el invierno o para el verano; desaparecerán los palacios de marfil y serán demolidas esas magníicas construcciones.

Am 4, 1: Esto es para ustedes, vacas de Basán, que viven en los ceros de Samaria: para usledes que oprimen a los débiles, aplasian a los menesterosos y dicen a sus maridos: "Sírvannos vino para emborrachamos".

Am 6, 3-6: Ustedes tratan de alejar el día de su desgracia, pero, en realidad, están apresurando un afto de violencia. Tendidos en camas de marfil o arrellenados sobre sus sofás, comen corderitos del rebafio y temeros sacados del establo, canturean al son del arpa y como David inventan instrumentos de música. Beben vino en grandes copas, con aceite exquisito se perfuman, pero no se afligen por el desastre de mi pueblo.

Am 6, 12 El reducirá a escombros la gran mansión y a un montón de ruinas, la pequeña.

Is 3, 18-24: Dice Yahveh: "Muy orgullosas andan las damas de Sión, con el cuello estirado y la mirada provocativa, y caminan a pasitos cortos haciendo sonar las pulseras de sus pies". Por eso el Señor llenará de sama la cabeza de las damas de Sión, y quedarán peladas. Aquel día, el Sefior arrancará los adornos, pulseras para los tobillos, cintas y lunetas, pendientes, brazaletes, velos, sombreros, cadenillas de pie, cinturones, frascos de perfume y amuletos, sortijas, aros de nariz, vestidos preciosos, mantos, chales y bolsos, espejos, lienzos finos, turbantes y mantillas. Aquel día, en lugar de perfumes habrá podredumbre, en lugar de cinturón, una cuerda, en lugar de cabello trenzado, cabeza rapada, en lugar de vestidos lujosos, un saco, en lugar de belleza, una marca hecha con hierro al rojo. 
Jr 22, 13-17: ¡Ay de aquel que construye su casa con cosas robadas, edificando sus pisos sobre la injusticia! ¡Ay de aquel que se aprovecha de su prójimo y lo hace trabajar sin pagarle su salario! Tú piensas: "Me voy a construir un palacio inmenso, con pisos espaciosos, luego abriré ventanas y las cubriré con madera de cedro, toda pintada de rojo". ¿Acaso serás más rey con tener más cedro? A tu padre, Lle faltó acaso comida o bebida? Sin embargo, se preocupaba de la justicia y todo le salía bien. Juzgaba la causa del desamparado y del pobre. Yahveh te pregunta: "Conocerme, ino es acuuar de esa forma?". Pero tú no piensas sino en tu interés, y en derramar sangre, y mantener la opresión y la violencia. Eso sí que te gusta.

Contra las injusticias en la administración de justicia que produce que al pueblo se le arranque la piel y sea alimento de los ricos

Am 2, 6:

Porque venden al inocente por dinero y al necesitado por un par de sandalias.

Am 5, 7.12: ¡Ay de ustedes que transforman las leyes en algo tan amargo como el ajenjo y tiran por el suelo la justicia! Ustedes odian al que defiende lo justo en el tribunal y aborrecen al que dice la verdad. Pues yo sé que son muchos sus crimenes y enormes sus pecados, opresores de la gente buena, que exigen dinero anticipado y hacen perder su juicio al pobre en los tribunales.

Am 6, 13: ¿Galopan por las rocas los caballos o se ara el mar con bueyes, para que ustedes cambien en veneno el derecho o en ajenjo las sentencias del tribunal?

Mi 3, 1-3.9-11: Escuchen, jefes... ¿No deberían conocer lo que es justo? ¿Por qué, pues, odian el bien y aman el mal? Ustedes descueran vivos a los de mi pueblo y les arrancan su carne de sus huesos. Se comen la carne de mi pueblo, y parten sus huesos y los echan a la olla... Escuchen, gobernantes... ustedes que desprecian la justicia y tuercen manosamente la ley, Sión se está edificando sobre sangre, y Jerusalén, en base a crímenes. Sus gobemantes se dejan comprar para dar una sentencia; sus sacerdotes cobran por una decisión; sus profetas sólo vaticinan si se les paga, y lodos dicen que son amigos de Yahveh. Por eso exclaman "Si el Señor está con nosotros, ¿qué desgracia nos puede pasar?". 
Mi 7, 1-3: Pobre de mí, pues me parezco a los que recogen espigas después de la siega o a los que rebuscan racimos después de la vendimia, pero no hay ni un racimito para probarlo ni una de esas primeras brevas que me gustan. Los creyentes han desaparecido del país, y entre sus habitantes no se encuentra ni siquiera un hombre justo. Sus manos son buenas para hacer el mal: el príncipe es exigente; el juez se deja comprar; el poderoso decide lo que le conviene.

Is 1, 21-26: ¿Cómo es que pareces una prostituta, Sión, ciudad fiel que te conformabas a mis leyes? La justicia moraba en tus muros, pero te volviste barrio de asesinos. Tu plata se ha convertido en basura, tu vino estŕ mezclado con agua. Tus jefes son unos rebeldes, amigos de ladrones. Todos esperan recompensa y van detrás de los regalos. No hacen justicia al huérfano ni atienden la causa de la viuda. Escuchen, pues, la sentencia del Señor Yahveh, el Fuerte de Israel: "Me desquitaré con mis adversarios, yo me vengaré de mis enemigos. Volveré mi mano contra ti y te limpiaré de tus impurezas en tu horno, hasta quitarte todo lo sucio que tengas. Haré a tus gobernantes como eran antes, y a tus consejeros como en otros tiempos. En adelante te llamarán: Ciudad de la Justicia, Ciudad Fiel".

Is 5, 20.23: ¡Ay de aquellos que llaman bien al mal y mal al bien, que cambian las tinieblas en luz y la luz en tinieblas, que dan lo amargo por dulce y lo dulce por amargo! ¡Ay de aquellos que perdonan al culpable por dinero y privan al justo de sus derechos!

Is 10,1-2: iAy de aquellos que dictan leyes injustas y con sus decretos organizan la opresión, que despojan de sus derechos a los pobres de mi país e impiden que se le haga justicia, que dejan sin nada a la viuda y se roban la herencia del huérfano.

Jr 21, 11-12: A la familia real...: Hagan justicia correctamente, cada día, libren al oprimido de las manos de su opresor.

Jr 22, 1-3: Escucha la palabra de Yahveh, rey..: Practiquen la justicia y hagan el bien: libren de la mano del opresor al que fue despojado; no maltraten al emigrante ni al huérfano ni a la viuda; no les hagan violencia, ni derramen sangre inocente en este lugar.

Contra los comerciantes que engañan, especulando. a los pobres

Am 8, 4-6: A ustedes me dirijo, explotadores del pobre que quisieran hacer desaparecer a los humildes. No son ustedes los que dicen 
“¿Cuándo pasará la fiesta de la luna nueva o cuándo terminará el sábado, para que podamos vender nuestro trigo o abrir nuestras bodegas de cereales, pues nos irá tan bien que venderemos hasta el deshecho?". Ustedes sólo piensan en robarle al kilo, o en cobrar de más, usando balanzas falseadas. Ustedes juegan con la vida del pobre y del miserable por algún dinero o por un par de sandalias.

Mi 6, 9-12: Resuena la voz de Yahveh en la ciudad... Escúchenla, pueblo y sus gobernantes: "¿Tiene todavía en su casa el malvado tesoros adquiridos injustamente, y se sirve aún de una medida falsa para medir? ¿Voy a aceptar que use balanzas inexactas 0 que no pese en su bolsa el peso justo?". Que escuche esa ciudad, cuyos ricos se enriquecen en base a crímenes, y cuyos habilantes mienten de tal forma que su lengua sólo pronuncia mentiras.

\subsection{El anuncio profético del Dios de la Vida}

Junto a las denuncias que hacen los profetas de los diferentes ídolos de muerte, ya van anunciando de algun modo cómo adorar y dar culto al verdadero Dios, el de la Vida. Se podrían ir siguiendo en este sentido los mismos cinco apartados anteriores de denuncia y los mismos texlos y descubrííamos cómo uras cada denuncia del ídolo de muerte va ya un anuncio del camino a seguir para dar culto al verdadero Dios de la vida.

Por ejemplo: se hablaba de los ídolos que llevan a la muerte y se llamaba en seguida a seguir al Dios de la Vida ( $c f r$. Jr 10,10$)$ o bien se denunciaba el culto alienante porque iba acompañado de derramamiento de sangre y venía a continuación la llamada a practicar la justicia y la solidaridad (cfr. Is 1, 16-17).

No lo vamos a hacer así. Vamos sencillamente a ver algunos textos en que va apareciendo este anuncio del Dios de la Vida y en que se va mostrando el camino a seguir para que haya realmente más vida y se honre en consecuencia a dicho Dios.

Vamos a ver cómo los profetas anuncian dónde se encuentra el auténtico Dios. Tal como ellos afirman con fuerza, se encuentra siempre que hay paso de la esclavitud a la libertad plena y comparida, siempre que hay justicia y paz, siempre que hay solidaridad fraternal y comunión, siempre que se dé un cambio del corazón humano para que lata al unísono con el corazón misericordioso de Dios, siempre que se vayan realizando progresivamente los sueños y los proyectos de Dios (nuevos cielos y tierra, paraíso, reino de Dios). Veamos cómo lo van formulando los diferentes profelas.

¡Busquen a Yahveh y vivirán...! ¡Busquen el bien, no el mal, para que vivan, 
y así sea con ustedes Yahveh..., tal como dicen! ¡Aborrezcan el mal, amen el bien, implanten el juicio en la Puerta...! (Am 5, 6a.14-15).

Yo te desposaré conmigo para siempre; te desposaré conmigo en justicia y en derecho, en amor y en compasión; te desposaré conmigo en fidelidad, y tú conocerás a Yahveh (Os 2, 21-22).

Lo que yo quiero es amor y no sacrificios, conocimiento de Dios y no holocaustos (Os 6, 6).

Aprendan a hacer el bien, busquen lo justo, den sus derechos al oprimido, hagan justicia al huérfano, aboguen por la viuda (Is 1,17 ).

Porque el yugo que les pesaba sobre su hombro, la vara de su tirano, has roto, como el día de Madián. Porque toda bota que taconea con ruido y el uniforme lleno de sangre serán quemados (Is 9, 3s).

(El mesias) no juzgará por las apariencias, ni sentenciará de ofdas. Juzgará con justicia a los débiles, y sentenciará con rectitud a los pobres de la tierra... Serán vecinos el lobo y el cordero... La vaca y la osa pacerán juntas... Hurgará el nifio de pecho en el agujero del áspid... Nadie hará dafio, nadie hará mal en todo mi santo cerro, porque la tierra estará llena de conocimiento de Yahveh (Is 11, 3-9).

Sucederá en días futuros que el monte de la casa de Yahveh será asentado en la cima de los montes... Confluirán a él todas las naciones... Dirán: "Vengan, subamos al monte de Yahveh... para que él nos ensente sus caminos...". Pues... de Jerusalén saldrá la palabra de Yahveh. El juzgará entre las naciones... Forjarán de sus espadas azadones y de sus lanzas hoces. No levantará espada nación contra nación, ni se ejercitarán más en la guerra (Is 2, 2 4).

Y sucederá aquel día que yo exurparé de en medio de ti a tus caballos y haré desaparecer tus caballeros; extirparé tus ciudades y demoleré todas tus fortalezas; extirpare de us manos las hechicerías... y ya no podrás postrarte ante la obra de us manos (Mi 5, 9-12).

Se te ha declarado, hombre, lo que Yahveh te pide: tan sólo practicar la justicia, amar con temura solidaria y caminar humildemente con tu Dios (Mi $6,8)$.

Yo recogeré el resto de mis ovejas... las haré tornar..., criarán... Y pondré al frente de ellas pastores que las apacienten, y nunca más estarán medrosas ni asustadas, ni faltará ninguna. Miren que dras vienen en que suscitare a David un germen justo: reinará... la justicia en la tierra. En sus días estará a salvo Judá e Israel vivirá en seguro... (Jr 23, 2-6)

...pactare con Israel... una nueva alianza...: pondré mi ley en su interior y 
sobre sus corazones la escribiré, y yo seré su Dios y ellos serán mi pucblo... todos cllos me conocerán (Jr 31, 31-34).

...yo mismo cuidaré de mi rebaño y velaré por él... Yo mismo apacentaré mis ovejas y las llevaré a reposar... Buscaré la oveja perdida..., curaré a la herida...; pero a la que está gorda y robusta la exlerminaré: las pastorearé con juslicia... y yo vendré a salvar a mis ovejas para que no estén más expuestas al pillaje; voy a juzgar entre oveja y oveja... Concluiré con ellos una alianza de paz, haré desaparecer de esta tierra las bestias feroces... ellos vivirán en seguridad en su suelo. Y sabrán que yo soy Yahveh, cuando despedace las barras de su yugo y los libre de la mano que los tiene esclavizados (Ez 34, 11-31).

Y les daré un corazón nuevo, infundiré en ustedes un espíritu nuevo, quitaré de su carne el corazón de piedra y les daré un corazón de came... Ustedes serán mi pueblo y yo seré su Dios (Ez 36, 26-28).

...el fruto de la justicia será la paz, el fruto de la equidad una seguridad perpetua (Is 32,17 ).

El Espíritu del Señor Yahveh eslá sobre mí, por cuanto que me ha ungido Yahveh. A anunciar la buena nueva a los pobres me ha enviado, a vendar los corazones heridos; a pregonar a los cautivos la liberación y a los reclusos la libertad... (Is 61, 1-2).

¿No será más bien este otro el ayuno que yo quiero: desatar los lazos de la maldad, deshacer coyundas del yugo, dar la libertad a los quebrantados y arrancar todo yugo? ¿No será partir al hambriento tu pan y a los pobres sin hogar recibir en tu casa? ¿Que cuando veas a un desnudo le cubras y de tu semejante no te apartes? (Is 58, 6-7).

Este es, pues, el anuncio profético de la ulopía de una sociedad y una humanidad sofiadas por Dios. Nos puede parecer que es imposible realizar estos sueños. Pero no es así. De hecho ya alguien los ha realizado y nos ha enviado a todos a seguirlos proclamanado y a intentar hacerlos realidad poco a poco: el gran profeta Jesús de Nazaret, nuestro hermano y Sefior.

\section{Conclusion}

Podemos decir, por tanto, que estorbaron y estorban aquellos que defienden la vida digna de las víctimas de la injusticia, de los oprimidos, de los empobrecidos, de los encarcelados, de los llevados a la muerte. Estorbaron y estorban aquellos que desenmascaran la mentira y la hipocresía del poder que dice defender al pueblo pero que en realidad sólo busca mantenerse en el poder. Estorbaron y estorban aquellos que denuncian a todos los que rodean al poder y que sólo buscan congraciarse con él. Estorbaron y estorban aquellos que desenmascaran la idolatría que supone la confianza en las alianzas militares con 
las superpotencias y en las armas. Estorbaron y estorban aquellos que sacan a la luz la falsedad de la religión a la que no corresponde una vida justa y solidaria. Estorbaron y estorban aquellos que se toman en serio su fe en el Dios de la Vida y su compromiso por intentar que se haga realidad su sueño y su utopia.

\section{Su persecución y/o muerte son auténtico martirio}

Aparentemente, todo lo anterior se queda en un nivel intramundano y poco tiene que ver con Dios o con la fe en Dios. Sin embargo, y a partir del testimonio bíblico, vamos a ver cómo ser perseguido y morir por todo ello es ser perseguido y morir dando testimonio del Dios de la Vida. Veámoslo en algunos ejemplos.

Gn 4: es Dios mismo quien defiende la vida de Abel.

2S 12: Natán, profeta de Dios, denuncia a David, el elegido de Dios, por la sangre derramada de Urias.

IR 21: Elías ataca, en nombre de Dios, a Ajab y Jezabel por el asesinato de Nabot.

Am 2,6b-8: denuncia las faltas contra el prójimo como faltas que profanan el mismo nombre de Dios.

Am 5, 21-25; 5, 4-6.14-15: dice que el único culto aceplado por Dios es el que va acompañado de la justicia interhumana.

Os 6, 6: $\quad$ "porque yo quiero amor solidario, no sacrificios; conocimiento de Dios, no holocaustos".

Is 1, 10-17: el profela afirma que a Dios le repugna loda la vida cúltica en el templo "porque hay sangre en sus manos. Lávense, purifíquense. Alejen de mis ojos sus malas acciones, dejen de hacer el mal y aprendan a hacer el bien. Busquen la justicia, den sus derechos al oprimido, hagan justicia al huérfano y defiendan la viuda".

Mi 6, 8: "Ya se te ha dicho, hombre, lo que es bueno y lo que el Señor te exige: tan sólo que practiques la justicia, que ames con ternura y que vivas humildemente con tu Dios".

Jr 7, 1-15: sermón en cl templo y contra cl templo.

Jr 22, 13-17: denuncia contra Joaquín I.

Is 58, 1-10: sobre el verdadero ayuno.

En los textos anteriores lo que vemos es que se trata de una defensa fruto de la fe y de la identificación entre Dios y los maltratados. Los profelas de siempre son, por tanto, perseguidos y/o asesinados porque defienden al Dios de la Vida, 
porque defienden la vida de los pobres contra los ídolos que exigen la muerte de éstos.

Son interesantes algunos textos sapienciales en los que también se confirma esta identificación entre el trabajo en favor de los pobres y la afirmación creyente de Dios.

Pr 14, 31:

Pr 15, 25:

Pr 17 ,5:

Pr 23, 10s:

"Oprimir a los débiles es ofender a su creador".

"Yahveh derriba la casa de los soberbios, pero levanta los cercos de la viuda".

"El que hace burla del pobre ofende a su creador, el que se ríe de un desdichado no quedará impune".

"No cambies los límites antiguos, no te apoderes del campo del huérfano, porque su Vengador es poderoso; El asumirá su querella en tu contra".

Sir 34, 18-35,24: ¿Un culto a Dios sin solidaridad? ¡No, gracias!

También en los Salmos encontramos algo parecido cuando se dice que Dios es el defensor de los pobres; éstos son su heredad, son algo tan propio que cuando los tocan a ellos están tocando a Dios mismo; y Dios reacciona de inmediato (Sal 10, 14; 68 ,6-7; 72, 12-14; 82, 3-4; 94, 5ss; 146, 6b-9).

La conclusión, por tanto, es que quien defiende hasta la muerte a los pobres y oprimidos, como han hecho siempre los profetas, está defendiendo la gloria a Dios.

4. Con su persecución y/o muerte queda claro el sentido de la vida del profeta

Ante la frecuente acusación de que ellos se lo han buscado, se han metido donde no debían, sufren la consecuencia de su pecado, la persecución y la muerte de los profetas lo que hace es clarificar el sentido de su vida: una vida de comunión con el Siervo sufriente de Dios y, por tanto, de comunión con Dios mismo y sus sentimientos de solidaridad con la humanidad sufriente.

El Siervo, por solidaridad con el pueblo de Dios, lo acompaña hasta el final, entrega su vida entera para que el pueblo agarre fuerzas, se sienta acompañado por su Dios y consiga así salir de la situación de dolor, de esclavitud, de desesperanza, de desánimo y de muerte.

En esta línea se pueden leer los cantos del Siervo.

Is 42, 1-9: Dios presenta a su Siervo y la misión de éste: la justicia, la solidaridad y la liberación.

Is 49, 1-6: El Siervo explica su vocación, su intimidad con Dios y su 
sentimiento de ser defendido por El. Ve su misión como una misión que no se cierra a su propio pueblo sino que está abierta a todas las naciones.

Is 50, 4-9: $\quad$ El Siervo sigue explicando y afirma que se siente como un discípulo fiel de Dios en medio del fuerte sufrimiento.

Is 52, 13-53, 12: El Siervo, por su muerte solidaria, alcanza la vida para sí mismo y para el pueblo entero que descubre de esta manera cuánto le quiere Dios.

Así pues, ante la sospecha y la mal interpretación de que los profetas mártires mueren porque han sido abandonados por Dios y ante la afirmación de que su proyeclo de vida no tiene sentido ni futuro, lo que queda claro es que en ellos Dios quiere mostrar, en último término, el sinsentido de la acción de los injustos y opresores, su grave error de interpretación, y el triunfo final de la justicia y de la vida (cfr. Sab 2, $10-3,3 ; 5,1-20$ ).

\section{En Jesús se unen radicalmente vida haciendo el bien y muerte}

En algunos textos del libro de los Hechos $(10,34-43 ; 2,22-24 ; 3,12-15)$ se hace un breve resumen de la acción de Jesús en la línea de los profetas y del mismo Siervo. Se habla también de cómo dicha vida de Jesús le lleva a la oposición de los poderosos y a la muerte en cruz. Se habla finalmente de que su muerte no es la última palabra, sino que ha sido semilla de vida y origen de comunidades luchadoras por la vida.

Esta unión existente que aparece entre acción en favor del bien y de la salud para los oprimidos y la muerte en cruz tiene su confirmación en muchos textos evangélicos en los que ante un milagro de Jesús, es decir, ante una acción de justicia y de solidaridad de Jesús respecto a los marginados, a los pobres, a los esclavizados, a los muertos, etc., los jefes se reúnen para ver cómo pueden acabar con Jesús. Algunos textos lo expresan muy bien.

Mi 12,9-14: Uas la curación de un hombre con la mano seca "los fariseos entonces salieron, y se reunieron para ver la manera de acabar con ell".

Mc 11, 15-18: Lras la expulsión de los vendedores del templo, "los jefes de los sacerdotes y los maestros de la Ley, al saber esto, se preguntaron cómo podrian deshacerase de él. Porque tenían miedo ya que su enseñanza producía gran impacto entre la gente".

Lc 4, 14-30: tras el discurso programático de Jesús comprometiéndose a liberar a todos los pobres y oprimidos, se da una no aceptación de los que estaban allí; sigue luego una provocación 
de Jesús y el intento de sus oyentes de matarlo.

Jn 5, 1-18: tras la curación del paralítico de la piscina de Betsaida, Jesús justifica su acción porque es la del Padre. La reacción de sus opositores queda muy bien expresada cuando se dice que "por eso tenían ganas de acabar con él, porque además de quebrantar la ley del sábado se igualaba a Dios llamándolo su propio Padre".

Jn 10, 33: los judíos agarran piedras para apedrearle y dicen "no te apedreamos por algun bien que hayas hecho sino porque siendo hombre insultas a Dios haciéndote pasar por Dios". El contexto de esta acción es precisamente que Jesús defiende sus acciones en favor de los pobres, ciegos, cojos, etc., diciendo que éstas son las obras de Dios.

Jn 11, 45-53: tras la resurrección de Lázaro, muchos judíos, conslatando que hace muchos milagros, tienen miedo, "y ese mismo día decidieron matarlo" (cfr. también Jn 7, 1; 7,19; 7, 25 donde aparece con claridad que de hecho si le buscaban para matarle).

Es de notar la unión que se da aquí entre su comprensión de Dios como Padre - su predicación del reino - sus acciones de justicia y de solidaridad en favor de los pobres, marginados y oprimidos - la persecución de que es objelo su muerte - su resurrección - la comunidad y corriente de seguidores que crea.

Es la misma unión que se dio en la actuación de los profecas del pueblo de Dios, en los profetas que ha habido a lo largo de la historia, y en los profetas que nosotros hemos conocido y conocemos.

\section{Conclusión}

Podemos concluir diciendo que nuesuros compañeros mártires fueron perseguidos y martirizados porque estorbaban - como los profetas y como Jesús-, porque defendian aquello que Dios más quicre (la vida digna de los pobres) y porque esto interpelaba y llamaba urgentemente a la conversión a quienes no quieren convertirse ni cambiar nada. Celebrarlos y recordarlos es un reto para todos nosotros que nos llamamos seguidores de Jesús de Nazaret. 